\title{
PENGARUH MAT PILATES EXERCISE TERHADAP FLEKSIBILITAS TUBUH
}

\author{
Bambang Trisnowiyanto
}

Jurusan Fisioterapi Politeknik Kesehatan Kemenkes.R.I. Surakarta

Jl. Kapten Adisumarmo Tohudan Colomadu Karanganyar Surakarta 57173

Email: trisnowiyanto@yahoo.co.id

\begin{abstract}
ABSTRAK
Otot yang tidak lentur mengakibatkan penurunan lingkup gerak sendi, sehingga menurunkan aktivitas gerak dasar manusia sehari-hari seperti duduk ke berdiri, berjalan, membungkuk, meraih sesuatu ke depan dan mengangkat beban. Fleksibilitas punggung berfungsi saat membungkuk dan mengangkat beban. Dengan meningkatnya fleksibilitas akan memperbaiki kemampuan fungsi gerak tubuh serta mengurangi risiko cidera akibat retriksi otot. Fleksibilitas dapat ditingkatkan dengan latihan Pilates. Mengetahui pengaruh latihan mat Pilates terhadap peningkatan fleksibilitas tubuh. Eksperimen kuasi dengan rancangan one group pre-post test with control, dengan penentuan subjek melalui kriteria inklusi dan eksklusi. 30 orang wanita berusia 30 hingga 50 tahun, yang terdiri dari 13 orang kelompok latihan mat Pilates dan 17 orang kelompok control. program mat Pilates exercise selama 50 menit setiap sesi latihan sebanyak 2 kali perminggu selama 6 minggu. Fleksibilitas badan dengan themodified schober test (MST). uji homogenitas dengan mann-whitney $p=0,702(p>0,05)$. Uji beda kelompok perlakuan dengan wilcoxon $p=0,001(p<0,05)$, uji beda pada kelompok kontrol $p=0,552(\mathrm{p}>0,05)$. Latihan mat Pilates selama 50 menit, 2 kali perminggu selama 6 minggu mampu meningkatan fleksibilitas tubuh wanita usia 20-50 tahun.
\end{abstract}

Kata kunci: latihan mat Pilates, fleksibilitas tubuh.

\begin{abstract}
Inflexible muscles might decrease the range of motion, which will reduce basic movements of daily activity, such as sitting to standing, walking, bending, reaching for something and lifting weights. Flexibility of back is needed when bending and lifting weights. The increase of back flexibility will improve the ability of the body's motor function and reduce the risk of injury due to muscle restriction. Flexibility can be improved by practicing Pilates. To understand the effect of Pilates mat exercises to increase flexibility of the body. A quasi-experimental design with one group pre-post test with control, with the determination of the subject based on inclusion dan exclusion criteria. 30 women aged 30 to 50 years, 13 people in Pilates mat exercise group and 17 people in control group. A Pilates mat exercise program for 50 minutes per session, 2 times a week for 6 weeks. The flexibility of the body using the modified Schober test (MST).
\end{abstract}


Homogenity test used Mann-Whitney test showed $\mathrm{p}=0.702(\mathrm{p}>0.05)$. Difference test used Wilcoxon test showed $p=0.001(p<0.05)$ in the treatment group and $p=0.552(p>0.05)$ in the control group. Pilates mat exercises for 50 minutes, 2 times per week for 6 weeks was able to increase the flexibility of body in women aged $20-50$ years.

Keywords: Pilates mat exercises, flexibility of the body

\section{PENDAHULUAN}

Otot yang tidak lentur mengakibatkan penurunan lingkup gerak sendi, sehingga menurunkan aktivitas gerak dasar manusia sehari-hari seperti duduk ke berdiri, berjalan, membungkuk, meraih sesuatu ke depan dan mengangkat beban (Walker, 2007). Fleksibilitas merupakan kemampuan untuk mendayagunakan otot dan sendi untuk bergerak seluas-luasnya tanpa disertai rasa tidak nyaman atau nyeri (Sudarsono, 2008). Sedangkan menurut Donatelli (2007) fleksibilitas adalah kemampuan otot dan tendon untuk memanjang tanpa disertai adanya keterbatasan sendi. Fleksibilitas tubuh secara general melibatkan ligamen, otot, sendi dan diskus intervertebralis pada punggung bawah (Alter, 1996). Tubuh yang memiliki flesibilitas akan memperkecil risiko cidera pada punggung mengingat punggung sebagai inti badan merupakan komponen tubuh yang mempunyai aktivitas gerak yang cukup tinggi. Fleksibilitas punggung berfungsi saat membungkuk dan mengangkat beban (Muzamil, 2006). Fleksibilitas dibedakan menjadi fleksibilitas statik aktif, fleksibilitas statik pasif dan fleksibilitas dinamik (Appleton, 1998). Dengan meningkatnya fleksibilitas akan memperbaiki kemampuan fungsi gerak tubuh serta mengurangi risiko cidera akibat retriksi otot (Ratnawati, 2010). Fleksibilitas dipengaruhi oleh faktor internal dan eksternal. Faktor internal meliputi elastisitas jaringan sekitar, tipe persendian, usia, jenis kelamin dan hormon. Sedangkan faktor eksternal terdiri dari adanya penyakit, suhu dan pakaian yang ketat (Gummerson, 1990, dikutip oleh Appleton, 1998). Faktor usia erat kaitannya dengan fleksibilitas tubuh. Fleksibilitas mencapai puncaknya pada akhir masa pubertas yaitu pada usia 18-22 tahun (Shinta, 2007). Dengan bertambahnya usia akan diiringi adanya proses menua yang dimulai pada usia 25 tahun (Fowler, 2003). Shinta (2007) menambahkan bahwa dalam proses menua terdapat perubahan jaringan kolagen, penurunan konsentrasi air yang menyebabkan terjadinya penurunan daya lentur otot dan jaringan sekitar sendi. Fleksibilitas dapat ditingkatkan dengan latihan peregangan seperti propioceptive neuromuscular fascilitation (PNF), balistik, tai chi, yoga dan Pilates (Nelson dan Kokkonen, 2007). Latihan pilates merupakan latihan penguluran dan penguatan pada daerah core yaitu daerah antara pelvik, perut dan punggung yang mempunyai tujuan meningkatkan kekuatan otot, fleksibilitas, daya tahan otot sehingga kestabilan tubuh dapat terjaga melalui kontrol tubuh, postur dan pernapasan (Bryden, 2009; Shah, 2013).

Latihan Pilates dapat diterapkan pada semua orang baik orang sehat maupun sakit di segala kalangan umur. Latihan ini bersifat aman dilakukan karena tidak terdapat gerakan melompat atau berlari sehingga tidak meningkatkan risiko trauma serta diikuti tanpa adanya penekanan yang berlebihan dan rasa nyeri pada sendi. Selain itu latihan Pilates juga dikombinasikan dengan latihan pernapasan sehingga menimbulkan efek daya tahan dan relaksasi pada tubuh (Brignell, 2004). Beberapa penelitian 
tentang Pilates yang berhubungan dengan fleksibilitas diantaranya penelitian Phrompaet et al (2010) dan Araujo et al (2011). Namun penelitian Wimer (1999) dalam Phrompaet et al (2010) menyebutkan bahwa tidak ada pengaruh latihan Pilates terhadap peningkatan fleksibilitas pada lansia. Terdapat dua bentuk latihan Pilates, yaitu mat dan apparartus exercise. Mat exercise merupakan latihan Pilates dasar yang dilakukan di lantai dengan menggunakan matras. Pada mat exercise biasanya partisipan dalam posisi duduk, terlentang atau tengkurap dan menggunakan gaya gravitasi untuk menstabilisasi core. Sedangkan pada apparatus exercise didesain untuk menvariasikan pola gerakan dan postur tubuh (Brignell, 2004). Manfaat latihan Pilates menurut Paterson (2009) untuk menurunkan berat badan, meningkatkan kekuatan otot-otot punggung dan perut, mencegah trauma, meningkatkan fleksibilitas, memperbaiki postur dan memperbaiki kondisi kardiovaskular, juga digunakan untuk mengatasi kondisi-kondisi seperti epilepsi, obesitas, multiple sklerosis, diabetes mellitus, osteoporosis, osteoartritis, hipertensi, asma, nyeri leher dan nyeri punggung bawah.

\section{Program Mat Pilates Exercise}

Berikut pelaksanaan mat Pilates exerciseyang terdiri dari latihan pemanasan, inti dan pendinginan: (1) Latihan pemanasan, pada latihan pemanasan ini dilakukan gerakan-gerakan peregangan pada tiap sendi diseluruh tubuh termasuk pada kepala, leher, lengan, punggung hingga tungkai untuk mempersiapkan jaringan tubuh untuk bergerak tanpa terjadi cidera selama latihan. Pemanasan dilakukan selama 5 menit pada setiap sesi latihan. (2) Latihan inti, program latihan inti mat Pilates exercise ini disusun sebagai berikut: Tabel 1.Program Latihan Pilates

\begin{tabular}{|c|c|c|c|c|c|c|c|}
\hline No & Gerakan & Frekuensi & Volume & Repetisi & Interval & Set & Durasi \\
\hline 1 & Lumbar stretch & $2 \mathrm{x}$ & 10 detik & $5 \mathrm{x}$ & 5 detik & 2 & 300 detik \\
\hline 2 & Spine stretch I & $2 x$ & 10 detik & $5 x$ & 5 detik & 2 & 300 detik \\
\hline 3 & Spine stretch II & $1 \mathrm{x}$ & 10 detik & $6 x$ & 5 detik & 2 & 180 detik \\
\hline 4 & Spine twist & $2 x$ & 10 detik & $4 x$ & 5 detik & 2 & 240 detik \\
\hline 5 & Child pose & $1 \mathrm{x}$ & 10 detik & $10 x$ & 5 detik & 2 & 300 detik \\
\hline 6 & The wind mill & $1 x$ & 20 detik & $4 \mathrm{x}$ & 5 detik & 2 & 200 detik \\
\hline 7 & The saw & $2 \mathrm{x}$ & 10 detik & $4 \mathrm{x}$ & 5 detik & 2 & 240 detik \\
\hline 8 & The mermaid & $2 \mathrm{x}$ & 10 detik & $4 \mathrm{x}$ & 5 detik & 2 & 240 detik \\
\hline 9 & Half curl & $1 x$ & 10 detik & $8 \mathrm{x}$ & 5 detik & 2 & 240 detik \\
\hline 10 & Tiny step & $2 x$ & 10 detik & $8 \mathrm{x}$ & 5 detik & 2 & 480 detik \\
\hline 11 & The hundred I & $10 \mathrm{x}$ & 1 detik & $8 x$ & 5 detik & 2 & 240 detik \\
\hline 12 & Rolling like a ball & $1 \mathrm{x}$ & 5 detik & $8 \mathrm{x}$ & 5 detik & 2 & 160 detik \\
\hline 13 & Rolling down & $2 \mathrm{x}$ & 10 detik & $8 \mathrm{x}$ & - detik & 2 & 320 detik \\
\hline 14 & Single leg circle & $10 x$ & 1 detik & $8 x$ & 5 detik & 2 & 240 detik \\
\hline 15 & Single leg stretch & $4 \mathrm{x}$ & 1 detik & $8 \mathrm{x}$ & - detik & 2 & 64 detik \\
\hline 16 & Double leg stretch & $1 \mathrm{x}$ & 10 detik & $8 x$ & 5 detik & 2 & 240 detik \\
\hline & \multicolumn{6}{|c|}{ Total durasi latihan inti dalam 1 sesi latihan } & 25 menit \\
\hline
\end{tabular}

Sumber : Ellsworth, 2009. 
a) Lumbar stretch

Tujuan dari gerakan ini adalah untuk penguluran otot quadratus lumborum, obliqus eksternus, erector spine. Posisi awal tidur terlentang, kedua tungkai dan kaki rapat, lutut ditekuk. Pelaksanaannya adalah lutut digerakkan ke samping kanan dan kiri sampai sendi panggul dan lutut menyentuh lantai.

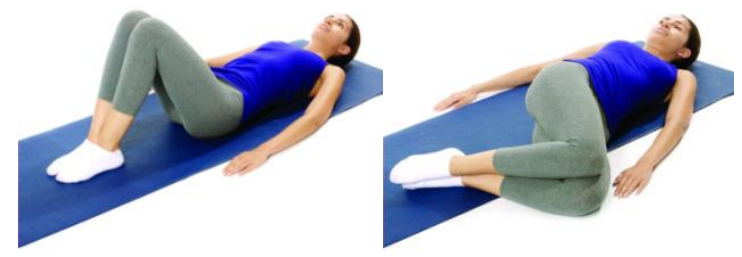

Gambar 1, Lumbar stretch (Ellsworth, 2009)

\section{b) Spine stretch I}

Tujuan dari gerakan ini adalah untuk mengulur otot vastus lateralis, iliotibial band, tensor fasiae latae. Posisi awal tidur terlentang, satu tungkai lurus dan satunya ditekuk. Kaki kanan diletakkan di atas tungkai kiri bawah.
Kedua lengan lurus tegak lurus dengan tubuh. Pelaksanaannya adalah tungkai yang ditekuk dibawa ke samping tubuh sisi berlawanan sampai punggung bawah terasa terulur. Selama gerakan kedua lengan tetap menempel di lantai.
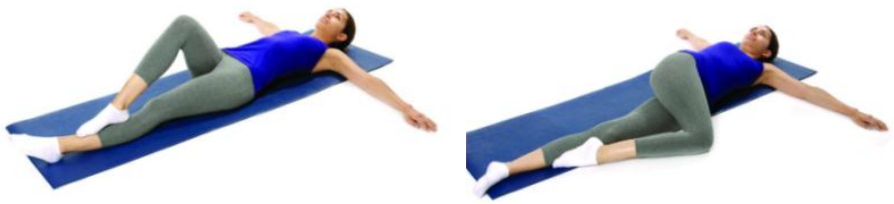

Gambar 2. Spine stretch I (Ellsworth, 2009)

c) Spine stretch II

Tujuan gerakan ini adalah untuk mengulur otot hamstring. Posisi awal duduk di atas matras, kedua tungkai diluruskan, kedua lengan lurus ke depan. Pelaksanaannya adalah tarik napas, lengan diulur ke depan dan tegak lurus dengan lantai. Selanjutnya hembuskan napas, membungkukkan punggung ke arah lutut seperti gerakan mencium lutut. Setelah itu hembuskan napas sambil menegakkan punggung kembali.

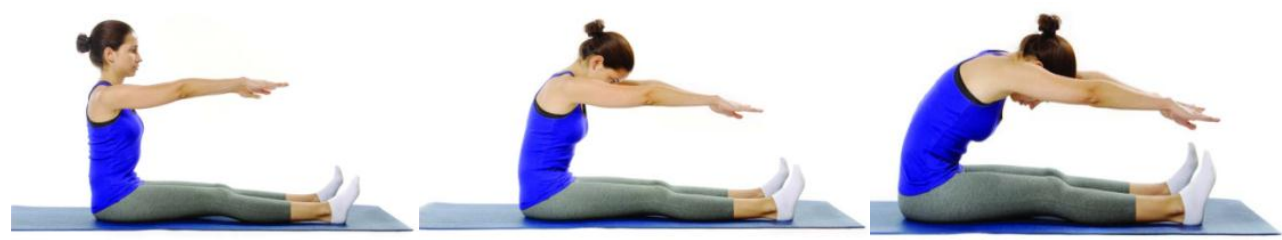

Gambar 3. Spine stretch II (Ellsworth, 2009)

\section{d) Spine twist}

Tujuan dari gerakan ini adalah untuk mengulur otot tranversus abdominis dan obliqus externus. Posisi awal duduk di atas matras, kedua tungkai lurus. Pelaksanaannya adalah tarik napas, lalu hembuskan napas, badan diputar ke arah kiri, sendi panggul tetap menyentuh matras. Selanjutnya tarik napas dan kembali ke posisi awal, dan hembuskan napas sambil mengulangi gerakan ke sisi kanan, lalu tarik napas dan kembali ke posisi awal. 


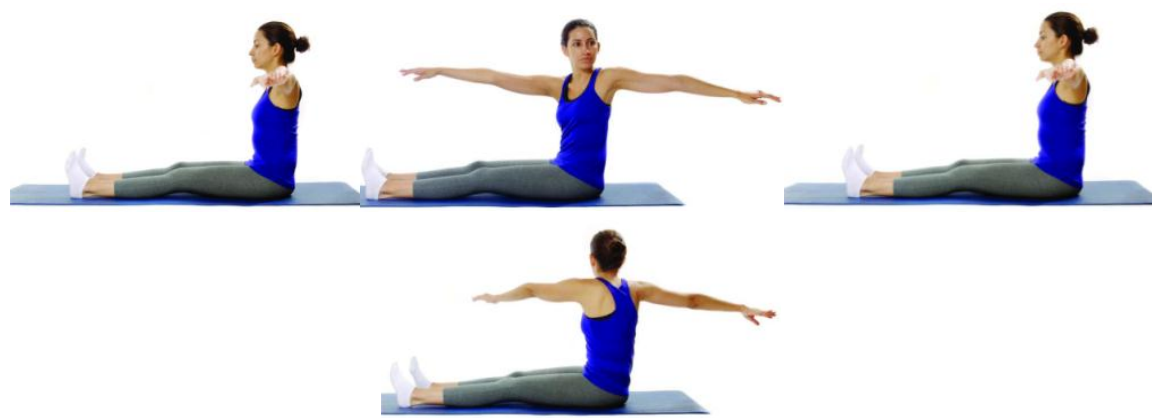

Gambar 4. Spine twist (Ellsworth, 2009)

e) Child pose

Tujuan gerakan ini adalah untuk mengulur otot-otot punggung bagian bawah. Posisi awal berlutut di atas matras, sendi panggul duduk di atas tumit, dada diturunkan di antara kedua paha. Pelaksanaannya adalah kepala ditundukkan, lengan diluruskan sampai di depan kepala dan diulur.
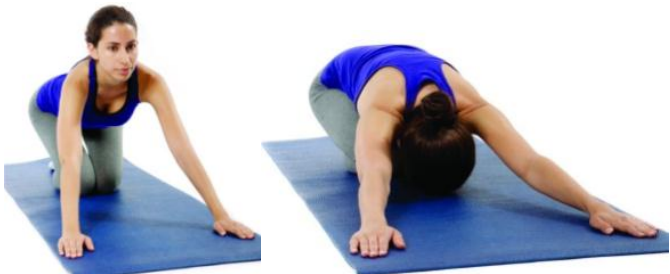

Gambar 5. Child pose (Ellsworth, 2009)

\section{f) The wind mill}

Tujuan gerakan ini adalah untuk mengulur otot punggung, otot hamstring dan otot gluteus maximus. Posisi awal berdiri tegap. Pelaksanaannya adalah menghembuskan napas, leher ditekuk ke bawah ke arah dada, tulang punggung satu
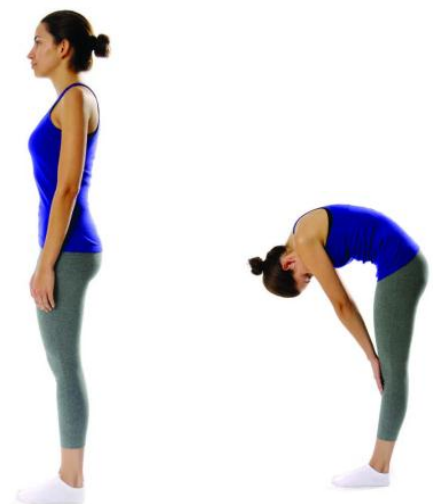

persatu dibungkukkan, pegang lutut dan tahan posisi, lalu lengan turun dan meraih jari kaki dan posisi ditahan. Berat badan dipindah ke depan. Setelah itu, tarik napas dan secara perlahan tulang-tulang punggung ditegakkan satu persatu hingga kembali ke posisi berdiri tegap.

Gambar 6. The windmill (Ellsworth, 2009)

\section{g) The saw}

Tujuan gerakan ini adalah untuk mengulur otot-otot pada tulang belakang. Posisi awal duduk di atas matras, tungkai lurus ke depan dengan lebar antara kedua kaki lebih lebar dari jarak antara sendi panggul. Kedua lengan direntangkan ke samping membentuk huruf $\mathrm{T}$ dan telapak tangan menghadap ke depan. Pelaksanaannya adalah tarik napas, lalu 
hembuskan napas sambil membungkukkan punggung dan meraih bagian luar tumit kiri dengan tangan kanan. Selanjutnya tarik napas lagi, lalu hembuskan, tangan semakin mengulur ke depan, kepala ditundukkan ke bawah dan bahu kiri menjauh dari telinga kiri. Kemudian tarik napas, kembali ke posisi awal, dilanjutkan dengan menghembuskan napas, dan melakukan gerakan yang berlawanan arah.

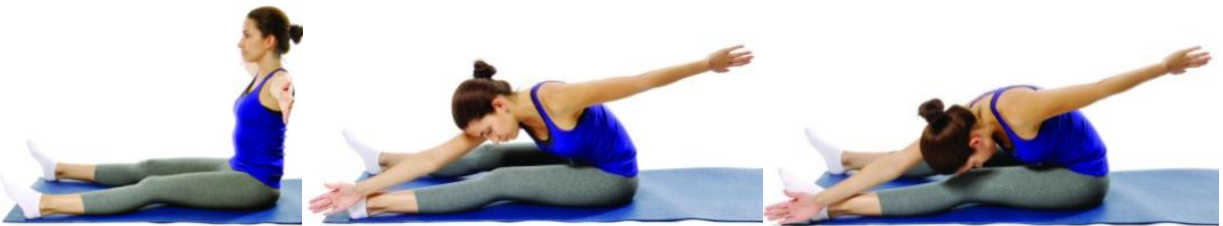

Gambar 7. The saw (Ellsworth, 2009)

\section{h) The mermaid}

Tujuan gerakan ini adalah untuk mengulur otot-otot tulang belakang dan membuka rongga dada. Posisi awal duduk dengan kedua lutut ditekuk dan tungkai bawah kanan menindih tungkai kiri, tangan kanan memegang pergelangan kaki. Pelaksanaannya adalah tarik napas, angkat lengan kiri ke atas setinggi mungkin. Kemudian hembuskan, lengan kiri dibawa ke samping kanan tubuh sambil mengencangkan perut. Selanjutnya tarik napas, dan kembali ke posisi awal.

Gambar 8. The mermaid (Ellsworth, 2009)

\section{i) Half curl}

Tujuan dari gerakan ini adalah untuk menguatkan core muscle, meningkatkan daya tahan otot perut. Posisi awal terlentang di atas matras, lutut ditekuk dan lengan lurus di samping tubuh. Kedua kaki dirapatkan dan permukaan kaki rata pada lantai. Pelaksanaannya adalah membungkukkan punggung atas dan bahu terangkat dari lantai dengan menggunakan otot perut atas, kedua lengan sejajar dengan lantai dan punggung bawah tetap menyentuh lantai.

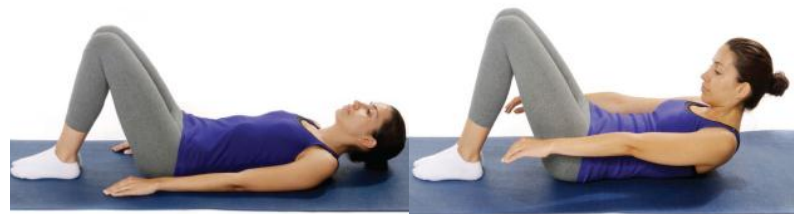

Gambar 9. Half Curl (Ellsworth, 2009)

j) Tiny step

Tujuan gerakan ini adalah untuk mengembangkan stabilitas otot perut, melindungi sendi panggul dan punggung bawah. Target utama gerakan adalah otot perut bawah. Posisi awal terlentang pada matras, lutut ditekuk dan kaki jinjit, kedua tangan berada di sendi panggul untuk 
merasakan gerakan tungkai. menahan posisi, lalu menghembuskan Pelaksanaannya adalah menghembuskan napas lagi sambil mengencangkan perut. napas, lalu lutut kanan diangkat ke arah Kaki diturunkan secara perlahan. Lalu dada sambil mengencangkan perut. melakukan gerakan yang sama pada Dilanjutkan dengan menarik napas dan tungkai kiri.

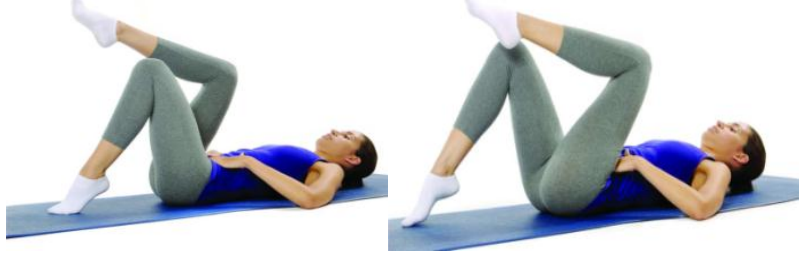

Gambar 10. Tiny step (Ellsworth, 2009)

\section{k) The hundred I}

Tujuan dari gerakan ini adalah untuk penguatan otot perut. Posisi awal terlentang di atas matras lutut ditekuk dengan permukaan kaki menempel pada lantai dan rapatkan paha. Pelaksanaannya adalah tarik napas, tangan dijulurkan ke arah depan dengan palmar tangan mengarah ke bawah. Lalu napas dihembuskan, lengan diangkat sehingga otot leher terulur dengan mengangkat kepala. Secara gentle dorong tangan ke atas sambil menarik napas dan ke bawah sambil menghembuskan napas dengan gerakan kecil seperti menepuk air. Selanjutnya adalah menarik napas sambil menggerakan tangan.Secara perlahan menghembuskan napas secara paksa dengan menggunakan otot perut.
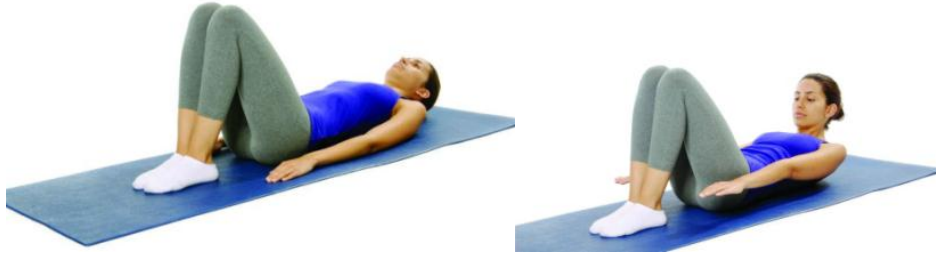

Gambar 11. The hundred I (Ellsworth, 2009)

\section{1) Rolling like a ball}

Tujuan dari gerakan ini adalah untuk meningkatkan kontrol otot perut. Posisi awal duduk dengan lutut ditekuk, kaki terangkat dari lantai, setelah posisi seimbang, kedua tangan diletakkan di bawah lipatan lutut. Pelaksanaannya adalah tarik napas, lalu sendi panggul diangkat dengan mengkontraksikan otot perut sambil berguling ke belakang perlahan-lahan sampai bahu menempel di atas lantai. Lalu napas dihembuskan dengan menggunakan otot perut berguling ke depan dengan menjaga keseimbangan. Bahu tetap dalam keadaan relaks selama gerakan dilakukan.

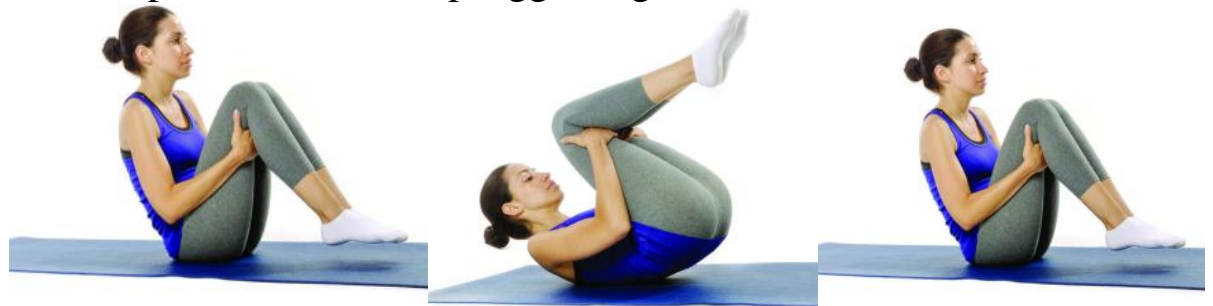

Gambar 12. Rolling like a ball (Ellsworth, 2009) 
m) Rolling down

Tujuan dari gerakan ini adalah untuk meningkatkan kekuatan otot perut dalam, mengulur otot punggung, mengembangkan kontrol core. Posisi awal duduk tegak pada matras, dengan lutut ditekuk dan telapak kaki menumpu pada lantai. Pelaksanaannya menarik napas sambil menegakkan tubuh setinggi mungkin, Selanjutnya hembuskan napas dan gulingkan punggung ke arah matras, tetap jaga agar kaki tetap menempel pada lantai. Gerakan dilakukan sampai punggung menempel pada matras, lalu kembali ke posisi awal.

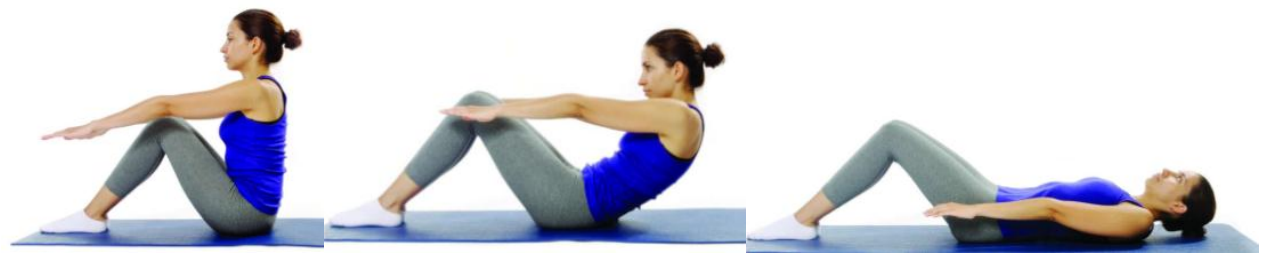

Gambar 13. Rolling down (Ellsworth, 2009)

n) Single leg circle

Tujuan gerakan ini adalah untuk mengulur otot tungkai, menguatkan otot perut dalam, dan stabilitas pelvik dan otot perut. Posisi awal terlentang pada matras, kedua tungkai lurus. Pelaksanaanya adalah tarik napas dan menghembuskan napas, tungkai kanan diangkat, buat lingkaran dengan lutut searah jarum jam dengan posisi lutut ditekuk. Dilanjutkan dengan menarik napas kembali, lalu menghembuskan napas, tungkai kiri membentuk lingkaran dengan arah berlawanan dengan yang sebelumnya
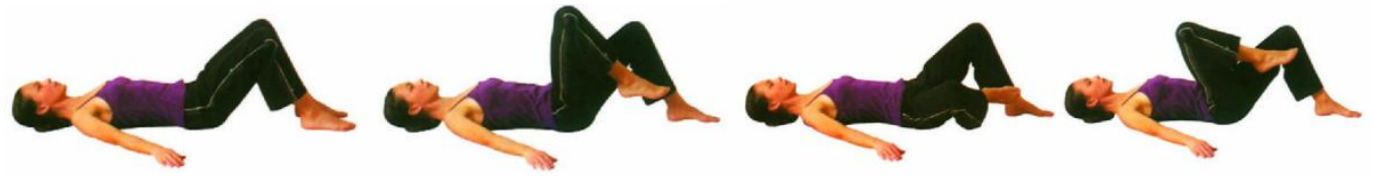

Gambar 14. Single leg circle (Brignell, 2004)

\section{o) Single leg stretch}

Tujuan dari gerakan ini adalah untuk menstabilkan core saat anggota gerak bawah digerakkan, dan menguatkan otot perut. Posisi awal tidur terlentang di atas matras. Pelaksanaannya adalah tungkai kanan diangkat ke arah dada. Tangan kanan menyentuh pergelangan kaki kanan dan tangan kiri menyentuh lutut kanan sambil mengangkat kepala lalu tungkai kiri diluruskan dan diangkat setinggi telinga dari matras.

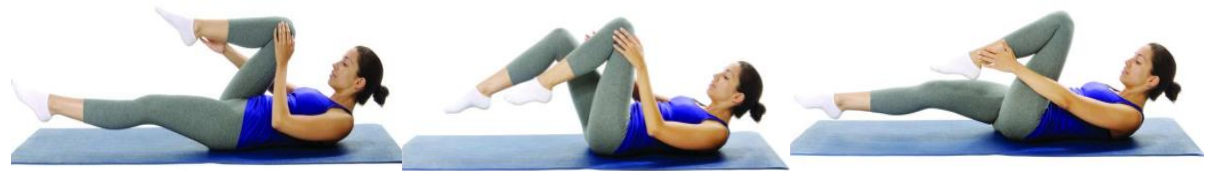

Gambar 15. Single leg stretch (Ellsworth, 2009)

\section{p) Double leg stretch}

Tujuan dari gerakan ini adalah untuk mengulur otot tungkai, menguatkan otot perut. Target utama gerakan ini adalah otot perut. Posisi awal terlentang di matras, lalu lutut didorong ke arah dada, kepala dan punggung atas diangkat, kedua tangan memegang pergelangan kaki.
Pelaksanaannya tarik napas, lalu kedua lengan terangkat dan terulur sejajar dengan matras dan luruskan tungkai ke atas, selanjutnya menghembuskan napas sambil memeluk lutut kembali ke arah dada. Pastikan punggung atas terangkat dari matras. 


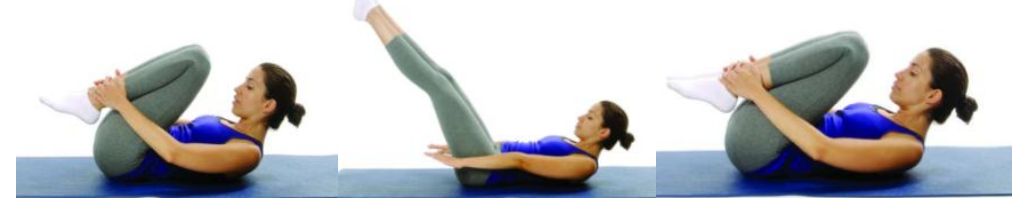

Gambar 16. Double leg stretch (Ellsworth, 2009)

(3) latihan pendinginan, pada latihan ini dilakukan gerakan penguluran ringan pada tiap sendi seperti pada kepala, leher,

\section{PENELITIAN YANG RELEVAN}

Penelitian Phrompaet et al (2010) mengenai efek latihan mat Pilates sebanyak $2 x$ per-minggu selama 8 minggu untuk meningkatkan fleksibilitas yang diukur dengan sit and reach test dan penelitian dilakukan secara randomized single blinded-control pada 40 subyek laki-laki dan perempuan sehat usia 24-39 tahun menyimpulkan bahwa latihan mat Pilates dapat meningkatkan fleksibilitas. Sedang penelitian Araujo et al (2011) mengenai latihan mat pilates sebanyak $2 \mathrm{x}$ perminggu selama 12 minggu untuk meningkatan fleksibilitas pada 31 wanita usia 18-25, dengan pengukuran fleksibilitas menggunakan goniometer menyebutkan bahwa mat Pilates dapat meningkatan fleksibilitas sebesar $80 \%$ pada kelompok perlakuan.

\section{METODE PENELITIAN}

Penelitian eksperimen kuasi dengan rancangan one group pre-posttest with control. Subjek penelitian adalah wanita dengan kriteria inklusi (1) usia 3050 tahun (2) tidak sedang menderita nyeri pada punggung bawah, (3) tidak menyandang disabilitas tulang belakang seperti lordosis, kyposis maupun scoliosis. kriteria ekslusi: (1) subyek tidak mampu berdiri dan berjalan, (2) subjek sudah memiliki program senam /olahraga rutin. lengan, punggung disertai pernapasan dalam untuk mengembalikan kondisi tubuh kembali rileks.

Subjek akan di drop out bila: (1) subjek absen latihan lebih dari 2 kali berturutturut. Alat ukur yang digunakan untuk mengukur fleksibilitas adalah themodified schober test, yang akan diukur saat sebelum dan sesudah perlakuan selama 6 minggu, kelompok perlakuan diberi program mat Pilates exercise selama 50 menit setiap sesi latihan sebanyak 2 kali perminggu selama 6 minggu.

\section{HASIL DAN PEMBAHASAN}

Penelitian ini melibatkan 41 wanita berusia 30 hingga 50 tahun. Subjek terdiri dari 21 orang pada kelompok latihan mat Pilates dan 20 orang kelompok kontrol. Pengelompokkan subjek dilakukan dengan undian yang terdiri dari nomor 1 dan 2. Subjek yang mendapatkan nomor 1 dimasukkan pada kelompok latihan mat Pilates dan subjek yang mendapatkan nomor 2 dimasukkan pada kelompok kontrol. Selama proses penelitian terdapat 8 orang drop out sedang pada kelompok kontrol 3 orang tidak mengikuti pengukuran post test.

Karakteristik subjek berdasarkan usia didapatkan hasil bahwa rerata usia pada kedua kelompok relatif berimbang. Pada kelompok perlakuan rerata usia 43 tahun, sedangkan kelompok kontrol rerata usia 38,59 tahun. 
Tabel 2. Karakteristik Subjek Berdasarkan Usia

\begin{tabular}{ccc}
\hline Data & $\begin{array}{c}\text { Kelompok I } \\
(\mathrm{n}=13)\end{array}$ & $\begin{array}{c}\text { Kelompok II } \\
(\mathrm{n}=17)\end{array}$ \\
\hline Minimum & 35 & 30 \\
Maksimum & 50 & 50 \\
Rata-rata & 43,00 & 38,59 \\
Standar Deviasi & 5,37 & 6,14 \\
\hline
\end{tabular}

Sumber: data primer

Nilai fleksibilitas sebelum perlakuan dan $5,62 \mathrm{~cm}$ pada kelompok perlakuan pada kedua kelompok relatif control. sama yakni rerata $5,44 \mathrm{~cm}$ pada kelompok

Tabel 3. Data Nilai Fleksibilitas Sebelum Perlakuan dalam Centimeter

\begin{tabular}{ccc}
\hline Data & Kelompok Perlakuan & Kelompok Kontrol \\
\hline Minimum & 2 & 4 \\
Maksimum & 10 & 7,5 \\
Rata-rata & 5,44 & 5,62 \\
Standar Deviasi & 2,28 & 1,23 \\
\hline
\end{tabular}

Sumber: data primer

Nilai fleksibilitas sesudah rerata $6,72 \mathrm{~cm}$ pada kelompok perlakuan perlakuan pada kedua kelompok adalah dan $5,55 \mathrm{~cm}$ pada kelompok control.

Tabel 4. Data Nilai Fleksibilitas Sesudah Perlakuan dalam Centimeter

\begin{tabular}{ccc}
\hline Data & Kelompok Perlakuan & Kelompok Kontrol \\
\hline Minimum & 2 & 4 \\
Maksimum & 10 & 7,5 \\
Rata-rata & 6,72 & 5,55 \\
Standar Deviasi & 2,01 & 1,21 \\
\hline
\end{tabular}

Sumber: data primer

Selisih nilai rerata fleksibilitas sebesar $1,28 \mathrm{~cm}$ sedang pada kelompok sebelum dan sesudah perlakuan adalah control sebesar $-0,07 \mathrm{~cm}$. sebagai berikut: pada kelompok perlakuan

Tabel 5. Data Nilai Fleksibilitas Awal dan Akhir Perlakuan

\begin{tabular}{ccccccc}
\hline Data & \multicolumn{3}{c}{ Kelompok Perlakuan } & \multicolumn{3}{c}{ Kelompok Kontrol } \\
\cline { 2 - 7 } & $\begin{array}{c}\text { Fleksibilitas } \\
\text { awal }\end{array}$ & $\begin{array}{c}\text { Fleksibilitas } \\
\text { akhir }\end{array}$ & Selisih & $\begin{array}{c}\text { Fleksibilitas } \\
\text { awal }\end{array}$ & $\begin{array}{c}\text { Fleksibilitas } \\
\text { akhir }\end{array}$ & Selisih \\
Minimum & 2 & 2 & 0 & 4 & 4 & 0 \\
Maksimum & 10 & 10 & 0 & 7,5 & 7,5 & 0 \\
Rata-rata & 5,44 & 6,72 & 1,28 & 5,62 & 5,55 & $-0,07$ \\
Standar deviasi & 2,28 & 2,01 & 0,27 & 1,23 & 1,21 & 0,02 \\
\hline
\end{tabular}

Sumber: data primer

Berdasarkan hasil uji homogenitas dengan mann-whitney diperoleh $p=0,702$ $(p>0,05)$ maka dapat disimpulkan bahwa data memiliki varians sama atau homogen.
Uji beda dengan wilcoxon diperoleh $p=0,001 \quad(p<0,05) \quad$ artinya terdapat perbedaan yang bermakna antara sebelum dan sesudah perlakuan pada kelompok 
perlakuan dan uji beda pada kelompok control diperoleh $p=0,552(p>0,05)$, hal ini menunjukkan bahwa tidak terdapat perbedaan yang bermakna antara sebelum dan sesudah perlakuan pada kelompok kontrol. Sehingga disimpulkan bahwa perbedaan rerata fleksibilitas pada kelompok perlakuan terjadi akibat pemberian program latihan mat Pilates.

Pemberian latihan pilates berpengaruh terhadap fleksibilitas, hal ini sesuai dengan penelitian yang dilakukan oleh Phrompaet et al (2010) dan Araujo et al (2011) yang menunjukkan hasil bahwa latihan mat Pilates dapat meningkatkan fleksibilitas. Menurut Phrompaet et al (2010) latihan pilates merupakan kombinasi peregangan statis dan dinamis yang dilakukan secara perlahan sehingga terjadi pemanjangan otot diikuti oleh sendi, ligamen dan diskus intervertebralis. Otot tersusun miofibril yang di dalamnya terdapat sarkomer yang saling sejajar. Sarkomer merupakan unit kontraktil yang terdiri dari aktin dan miosin yang saling tumpang tindih. Dengan adanya gerakan peregangan tersebut maka aktin dan miosin yang awalnya saling tumpang tindih akan saling menjauh sehingga terdapat jarak di antara filamen tersebut. Selain itu dengan adanya perubahan ketegangan otot akibat gerakan peregangan akan mengaktivasi golgi tendon organs (GTO) pada tendon dan otot. Saat peregangan yang dilakukan hampir melampaui batas normal maka
GTO akan teraktivasi untuk mencegah terjadinya cidera pada otot dan tendon. Impuls dari GTO dibawa oleh $I \beta$ untuk dilanjutkan hingga ke korteks serebri untuk dipersepsikan. Impuls dari GTO juga dialirkan dari spinal cord menuju interneuron yang menimbulkan penurunan aktivitas alpamotor neuron sehingga ketegangan otot berkurang berupa sarkomer yang memanjang. Apabila gerakan penguluran dihentikan, sarkomer akan tetap memanjang sebagai proses adaptasi pemanjangan jaringan yang baru (Alter, 1996). Pada kartilago sendi, gerakan peregangan akan menstimulasi sekresi glikosaminoglikan (GAG) dan asam hialuronat yang kemudian akan membentuk enzim hialuronidase. Gerakan peregangan juga akan menyebabkan peningkatan konsentrasi air pada diskus intervertebralis. Selanjutnya GAG, asam hialorunat dan air akan menyebabkan jarak antar serabut bertambah, peningkatan pelumasan (lubrikasi) dan penurunan jaringan kolagen yang terisi oleh jaringan fibrous (Alter, 1996) sehingga fleksiblitas tubuh dapat meningkat.

\section{KESIMPULAN}

Latihan mat Pilates selama 50 menit, 2 kali perminggu selama 6 minggu mampu meningkatan fleksibilitas tubuh wanita usia 20-50 tahun.

\section{DAFTAR PUSTAKA}

Alter, M.J., 1996, Science of Flexibility; $2^{\text {nd }}$ ed, Human Kinetics, United States, hal 261268.

Appleton, B., 1998, Stretching and Flexibility "Everything You Never Wanted to Know"; version: 1.42, last modified 98/06/10, http//www.enteract.com/users/bradapp/rec/stretching/, diakses tanggal 11 Maret 2015 
Araujo, M.E.A., Silva, E.B., Mello, D.B., Cader, S.A., Inoue, S., Dantas, E.H.M., 2011, The Effectiveness of Pilates Method : Reducing the Degree of Non Structural Scoliosis and Improving Flexibility and Pain In Female College Students, www.elsevier.com/jbmt, diakses tanggal 28 Maret 2015.

Brignell, R., 2004, The Pilates Handbook, Rosen Publishing, New York.

Bryden \& Lincoln., 2009, Stability Ball Exercises, www.fitnesstrainingforlife.com, diakses tanggal 6 April 2015.

Donatelli, R., 2007, Sports-Specific Rehabilitation; Churchill Livingstone Elsevier, Unites States of America, hal 42-43.

Ellsworth, A., 2009, Pilates Anatomy : a Comprehensive Guide, Thunder Bay Press, California.

Fowler, B., 2003, Functional and Biological Markers of Aging, the A4M Publications, Chicago, hal 43.

Muzamil ,M.A., 2006, Perbandingan Efek Pengobatan Parasetamol dan Diasepam dengan Natrium Diklofenak terhadap Derajat Nyeri dan Fleksibilitas Otot pada Nyeri Pinggang Non Spesifik Akut, Tesis PPDS, Universitas Diponegoro, Semarang.

Nelson, A.G \& Kokkonen, J., 2007, Stretching Anatomy, Human Kinetics, Canada, hal IV.

Paterson, J., 2009, Teaching Pilates for Postural Faults, Illness \&Injury: a Practical Guide, Butterworth Heinemann Elsevier, Philadelphia.

Phrompaet, S., Paungmali, A., Pirunsan, U., Sitilertpisan, P., 2010, Effects of Pilates on Lumbopelvic Stability and Flexibility, Chiang Mai University, Thailand, hal 17.

Ratnawati, H.P., 2010, Pengaruh Senam untuk Mencegah Nyeri Punggung terhadap Fleksibilitas Lumbal pada Lanisa Di Organisasi Wanita Islam Kelurahan Sriwedari Kecamatan Laweyan Kota Surakarta, Universitas Muhammadiyah Surakarta, Surakarta, hal 3.

Shah, S., 2013, Pilates Exercise Review Article, International Journal of Physioterapy and Research, vol.4, India, hal 196.

Shinta, A., 2007, Pengaruh Latihan Hatha Yoga Selama 12 Minggu terhadap Fleksibilitas Static Wanita Berusia 50 Tahun Keatas, Universitas Diponegoro, Semarang.

Sudarsono, N. C., 2008, Kebugaran; http://seripay.wordpress.com//, diakses tanggal 28 Maret 2015 
Walker, B., 2007, Ultimate Guide to Stretching and Flexibility, $3^{\text {th }}$ ed., Injury Fix and Stretching Institute, United State. 